\title{
12. An assessment of DSS design science using the Hevner, March, Park and Ram guidelines
}

\author{
DAVID ARNOTT \\ MONASH UNIVERSITY \\ GRAHAM PERVAN \\ CURTIN UNIVERSITY OF TECHNOLOGY
}

\section{Abstract}

Design science has been an important strategy in decision support systems (DSS) research since the inception of the field in the early 1970s. Recent reviews of DSS research have indicated a need to improve its quality and relevance. DSS design science has an important role in this improvement as design science can engage industry and the profession in intellectually important projects. The 2004 publication of the Hevner, March, Park and Ram (HMPR) guidelines for the conduct and assessment of information systems design science provides a vehicle for assessing DSS design science. This chapter presents research that uses bibliometric content analysis to apply the HMPR guidelines to a representative sample of DSS design-science papers in 14 journals. The analysis highlights issues that need attention - notably, evaluation, research design, strategic focus and theorising. Comments are also offered on the experience of applying the HMPR guidelines to a large body of research.

\section{Introduction}

Decision support systems (DSS) is the area of the information systems (IS) discipline that is focused on systems that support and improve managerial 
decision making in terms of contemporary professional practice. Arnott and Pervan (2008) identify seven DSS types that are separated by technology, theory foundations, user populations and decision tasks.

- Personal Decision Support Systems (PDSS) are usually small-scale systems that are developed for one manager, or a small number of independent managers, to support a decision task. Perhaps the oldest DSS type, PDSS remains important in practice, especially in the form of user-built models and data-analysis systems (Arnott 2008).

- Group Support Systems (GSS) 'consists of a set of software, hardware, and language components and procedures that support a group of people engaged in a decision-related meeting' (Huber 1984). GSS are typically implemented as electronic meeting systems (EMS) (Dennis et al. 1988) or group decision systems (GDS) (Pervan and Atkinson 1995).

- Negotiation Support Systems (NSS) are DSS that operate in a group context, but, as the name suggests, they involve the application of information technology (IT) to facilitate negotiations (Rangaswamy and Shell 1997). As the group members in NSS are opposing parties, NSS has had to be developed on a different theory foundation to that of GSS.

- Intelligent Decision Support Systems (IDSS) involve the application of artificial intelligence techniques to decision support. IDSS can be classed into two generations: the first involves the use of rule-based expert systems for decision support, and the second uses neural networks, genetic algorithms and fuzzy logic (Turban et al. 2005).

- Knowledge Management-Based DSS (KMDSS) are systems that support decision making by aiding knowledge storage, retrieval, transfer and application. KMDSS can support individual and organisational memory and inter-group knowledge access (Burstein and Carlsson 2008).

- Data Warehousing ( $D W$ ) provides the large-scale data infrastructure for decision support. In general terms, a data warehouse is a set of databases created to provide information to decision makers. In practice, data warehousing includes enterprise data warehouses, data marts and applications that extract, transform and load (ETL) data into the data warehouse or mart (Watson 2001).

- Enterprise Reporting and Analysis Systems (ERAS) are enterprise-scale systems that include executive information systems (EIS), online analytical processing systems (OLAP), business intelligence (BI) and, more recently, corporate performance management systems (CPM). BI tools access and analyse data warehouse information using predefined reporting software, query tools and analysis tools (Nelson et al. 2005). 
In the nearly four decades of its history, DSS has moved from a radical movement that changed the way information systems were perceived in business to a mainstream commercial IT movement that all organisations engage. During this time, DSS has continued to be a significant sub-field of IS scholarship.

Design science is an alternative - or a complement - to the natural science approach that is dominant in IS research. In design science, the researcher 'creates and evaluates IT artifacts intended to solve identified organisational problems' (Hevner et al. 2004:77). March and Smith (1995:253) clearly draw a distinction between natural and design science: 'Whereas natural science tries to understand reality, design science attempts to create things that serve human purposes.' Design science is particularly relevant for contemporary IS research because it could help researchers confront two of the major challenges of the discipline: the role of the IT artefact in IS research (Orlikowski and Iacono 2001) and the low level of professional relevance of many IS studies (Benbasat and Zmud 1999). The terminology of design science is gaining momentum in IS. March and Smith (1995) were the first major users of the term in IS, although 'design theory' was used earlier (Walls et al. 1992). The landmark publication is Hevner et al. (2004), who proposed a set of seven guidelines to assess designscience research in IS. The publication of the guidelines in MIS Quarterly is particularly symbolic. A prescriptive design-science methods paper in the most cited IS journal will be influential with journal editors and reviewers, and it is also likely to be used by $\mathrm{PhD}$ examiners for IS design-science theses.

DSS research has a long history of using design-science strategies and many of the early DSS projects involved designing and implementing innovative ITbased systems (for example, Meador and Ness 1974; Keen and Gambino 1983). General reviews of DSS research have pointed to a need to increase the rigour of DSS design-science research (Arnott and Pervan 2005, 2008). One way to improve the quality of DSS design science - and to improve its contribution to general IS research - is to systematically review published projects and identify strategies for improvement. That is the goal of this chapter.

\section{Research method and design}

There are two fundamental strategies for literature analysis. The first - thematic analysis - involves classifying and analysing papers according to themes that are relevant to the theory and practice goals of a research project (Webster and Watson 2002). Thematic analysis is by far the most common form of literature review in journal papers and theses. The second fundamental strategy is bibliometrics, which involves the measurement of publication patterns. The two most common bibliometric methods are citation analysis (Osareh 1996) and 
content analysis (Weber 1990). In DSS literature analysis, Sean Eom's series of studies has used citation analysis to analyse the intellectual structure of the field (Eom 1995, 1996, 1999; Eom and Lee 1990, 1993). In bibliometrics, content analysis involves the coding and analysis of a representative sample of research articles. In this approach, data capture is driven by a protocol that can have both quantitative and qualitative aspects. This form of data capture is a very labour-intensive process but it has the advantage that it can illuminate the deep structure of the field in a way that is impossible to achieve with other literature analysis approaches. This research adopted a content analysis method to help understand the nature of DSS design-science research and to assess its strengths and weaknesses.

The sample of articles for this project is DSS research published between 1990 and 2005 in the 14 journals shown in Table 12.1. We adopted a large set of quality journals as a basis of the sample because we believe that this best represents the invisible college of DSS research. Previous analyses of IS research have used a similar sampling approach (Alavi and Carlson 1992; Benbasat and Nault 1990; Pervan 1998; Chen and Hirschheim 2004). Alavi and Carlson (1992) used eight North American journals for their sample. Webster and Watson (2002) have, however, criticised the over emphasis on North American journals in review papers. In response, we included five European IS journals (Information Systems Journal, European Journal of Information Systems, Information and Organization, Journal of Information Technology and Journal of Strategic Information Systems) in our sample. Following Chen and Hirschheim (2004), the classification of a journal as US or European is based largely on the location of the publisher.

The quality of journals was classified as 'A' level or 'Other'. This classification is based on publications that address journal ranking (Gillenson and Stutz 1991; Hardgrave and Walstrom 1997; Hirschheim 1992; Holsapple et al. 1994; Mylonopoulo and Theoharakis 2001; Walstrom et al. 1995; Whitman et al. 1999) and on discussions with journal editors and senior IS academics. Another indicator of journal quality is the Thomson ISI journal impact factor. The 2006 impact factors for 13 of the 14 journals in the sample are shown in Table 12.1. Information \& Organization is not in the Thomson ISI index.

The selection of the journal sample was the first stage in arriving at the DSS design-science sample. An overview of the sampling process is shown in Figure 12.1 . 


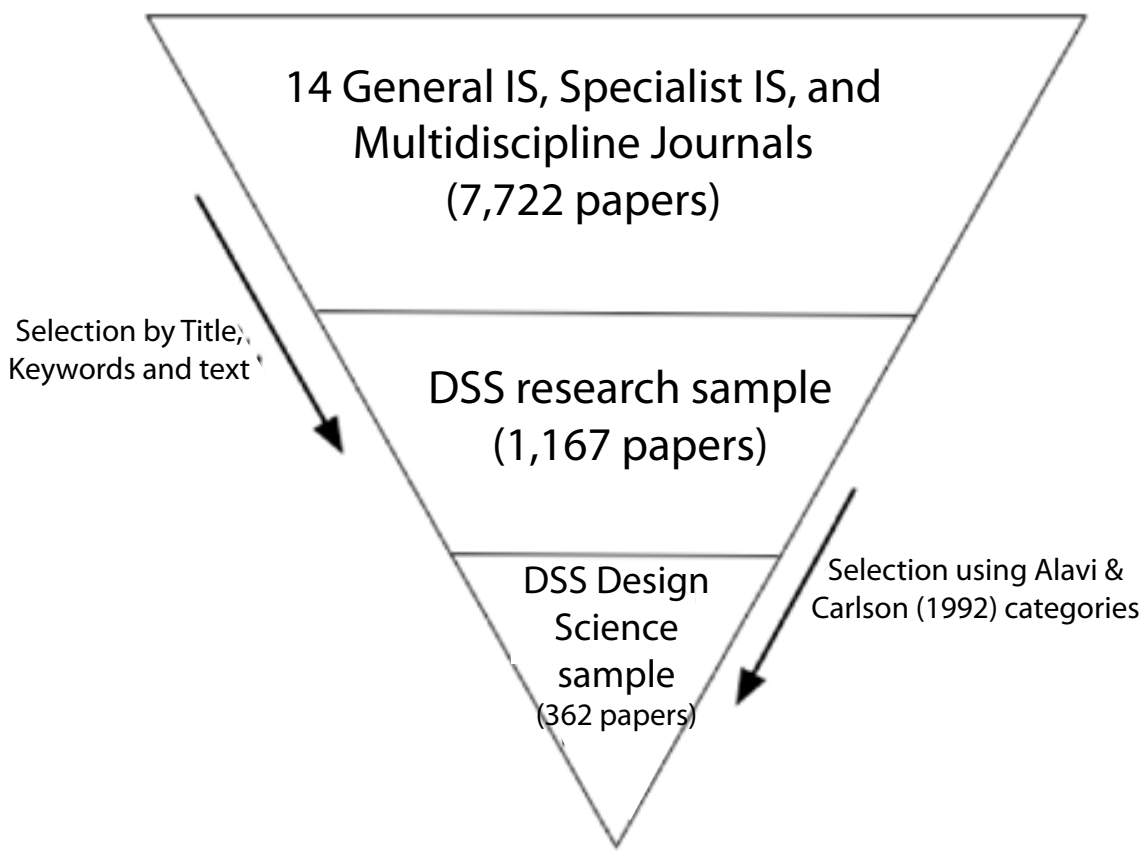

\section{Figure 12.1 Arriving at the DSS design-science sample}

The first stage of article sampling was to identify the DSS articles in the 14 journals. The papers were initially selected electronically by examining keywords and titles. A manual check was performed of the table of contents of each issue of each journal. In addition, the text of each potential article for analysis was examined to verify its decision support content in terms of definition of DSS provided above. This procedure identified 1167 DSS papers. Table 1.1 shows the distribution of the DSS papers in the sample by journal. Overall, 15.1 per cent of published papers in the 14 journals between 1990 and 2005 were in the DSS field. When only the general IS journals in the sample are examined, the proportion of DSS articles increases to 18.9 per cent. Each of these measures indicates that DSS is an important part of the IS discipline. 
Information Systems Foundations: The Role of Design Science

Table 12.1 DSS and DSS design-science article samples by journal

\begin{tabular}{|c|c|c|c|c|c|c|}
\hline Journal & Origin & $\begin{array}{l}\text { Ranking } \\
\text { (ISI impact } \\
\text { factor) }\end{array}$ & $\begin{array}{l}\text { Journal } \\
\text { orientation }\end{array}$ & $\begin{array}{l}\text { No of } \\
\text { DSS } \\
\text { articles } \\
\text { published }\end{array}$ & $\begin{array}{l}\text { DSS } \\
\text { design- } \\
\text { science } \\
\text { articles } \\
\text { published }\end{array}$ & $\begin{array}{l}\text { DSS } \\
\text { design- } \\
\text { science } \\
\text { articles } \\
\text { as a \% of } \\
\text { published } \\
\text { DSS } \\
\text { articles }\end{array}$ \\
\hline $\begin{array}{l}\text { Decision Sciences } \\
\text { (DS) }\end{array}$ & US & $A(1.620)$ & $\begin{array}{l}\text { Multi- } \\
\text { discipline }\end{array}$ & 67 & 19 & 28.4 \\
\hline $\begin{array}{l}\text { Decision Support } \\
\text { Systems (DSS) }\end{array}$ & US & $A(1.160)$ & General IS & 500 & 247 & 49.4 \\
\hline $\begin{array}{l}\text { European Journal } \\
\text { of Information } \\
\text { Systems (EJIS) }\end{array}$ & Europe & $A(0.862)$ & General IS & 25 & 5 & 20.0 \\
\hline $\begin{array}{l}\text { Group Decision } \\
\text { and Negotiation } \\
(G D \& N)\end{array}$ & US & $\begin{array}{l}\text { Other } \\
(0.429)\end{array}$ & $\begin{array}{l}\text { Specialist } \\
\text { IS }\end{array}$ & 139 & 24 & 17.3 \\
\hline $\begin{array}{l}\text { Information and } \\
\text { Management (I\&M) }\end{array}$ & US & $A(2.119)$ & General IS & 104 & 13 & 12.5 \\
\hline $\begin{array}{l}\text { Information and } \\
\text { Organization (I\&O) }\end{array}$ & Europe & $\begin{array}{l}\text { Other (not } \\
\text { abstracted) }\end{array}$ & General IS & 16 & 1 & 6.3 \\
\hline $\begin{array}{l}\text { Information } \\
\text { Systems Journal } \\
\text { (ISJ) }\end{array}$ & Europe & A (1.543) & General IS & 16 & 1 & 6.3 \\
\hline $\begin{array}{l}\text { Information } \\
\text { Systems Research } \\
\text { (ISR) }\end{array}$ & US & $\mathrm{A}(2.537)$ & General IS & 34 & 5 & 14.7 \\
\hline $\begin{array}{l}\text { Journal of } \\
\text { Information } \\
\text { Technology (JIT) }\end{array}$ & Europe & $A(1.239)$ & General IS & 25 & 2 & 8.0 \\
\hline $\begin{array}{l}\text { Journal of } \\
\text { Management } \\
\text { Information } \\
\text { Systems (JMIS) }\end{array}$ & US & $A(1.818)$ & General IS & 84 & 18 & 21.4 \\
\hline $\begin{array}{l}\text { Journal of } \\
\text { Organizational } \\
\text { Computing } \\
\text { and Electronic } \\
\text { Commerce } \\
\text { (JOC\&EC) }\end{array}$ & US & $\begin{array}{l}\text { Other } \\
(0.500)\end{array}$ & $\begin{array}{l}\text { Specialist } \\
\text { IS }\end{array}$ & 73 & 12 & 16.4 \\
\hline $\begin{array}{l}\text { Journal of Strategic } \\
\text { Information } \\
\text { Systems (JSIS) }\end{array}$ & Europe & $\begin{array}{l}\text { Other } \\
(0.971)\end{array}$ & General IS & 8 & 1 & 12.5 \\
\hline $\begin{array}{l}\text { Management } \\
\text { Science (MS) }\end{array}$ & US & $A(1.687)$ & $\begin{array}{l}\text { Multi- } \\
\text { discipline }\end{array}$ & 41 & 13 & 31.7 \\
\hline $\begin{array}{l}\text { MIS Quarterly } \\
\text { (MISQ) }\end{array}$ & US & $A(4.731)$ & General IS & 35 & 1 & 2.9 \\
\hline Total & & & & 1167 & 362 & 31.0 \\
\hline
\end{tabular}


Each of the 1167 papers was coded using the Alavi and Carlson (1992) taxonomy, as modified by Pervan (1998) to include action research and to distinguish between positivist and interpretative case studies. The result of this coding is shown in Table 12.2. The papers from the article types - 'Tools, techniques, methods, model application', 'Conceptual frameworks and their application', 'Description of type or class of product', 'Technology, systems, etc.' , 'Description of specific application, system, etc.' and 'Action rwesearch' - were inspected by both researchers to see if they met the design-science research definition of Hevner et al. (2004). In particular, each paper was inspected for a focus on an innovative artefact, rather than providing a description of an existing commercial product. This yielded a DSS design-science sample of 362 papers. This sample shows the importance of design science to DSS scholarship, as design science is the strategy of 31 per cent of DSS papers. To help identify trends in DSS design-science research, we divided the sample into four four-year eras: 1990-93, 1994-97, 1998-2001 and 2002-05.

The 362 DSS design-science papers were then coded using the protocol shown in Appendix 12.1. The protocol was based on the guidelines proposed by Hevner et al. (2004). The time taken to code each article varied from 20 minutes to more than one hour. To ensure coding validity, both researchers coded each paper; disagreements in coding were discussed and resolved. An important aspect of coding validity is that the two researchers have decades of experience in the DSS area, are experienced journal reviewers and editors and have published DSS design-science projects (for example, Arnott 2004, 2006).

Table 12.2 The DSS and DSS design-science samples by article type

\begin{tabular}{|c|c|c|c|c|c|c|c|}
\hline & & Article type & $\begin{array}{l}\text { DSS } \\
\text { (no.) }\end{array}$ & $\begin{array}{l}\text { Papers } \\
\text { (\% of } \\
\text { sample) }\end{array}$ & $\begin{array}{l}\text { DSS } \\
\text { (no.) }\end{array}$ & $\begin{array}{l}\text { Design } \\
\text { (\% of } \\
\text { sample) }\end{array}$ & $\begin{array}{l}\text { Science } \\
\text { (\% of } \\
\text { DSS) }\end{array}$ \\
\hline \multirow[t]{8}{*}{$\begin{array}{l}\text { Non- } \\
\text { empirical }\end{array}$} & \multirow[t]{4}{*}{$\begin{array}{l}\text { Conceptual } \\
\text { orientation }\end{array}$} & $\begin{array}{l}\text { DSS } \\
\text { frameworks }\end{array}$ & 53 & 4.5 & 0 & 0.0 & 0.0 \\
\hline & & $\begin{array}{l}\text { Conceptual } \\
\text { models }\end{array}$ & 30 & 2.6 & 0 & 0.0 & 0.0 \\
\hline & & $\begin{array}{l}\text { Conceptual } \\
\text { overview }\end{array}$ & 49 & 4.2 & 0 & 0.0 & 0.0 \\
\hline & & Theory & 22 & 1.9 & 0 & 0.0 & 0.0 \\
\hline & \multirow[t]{3}{*}{ Illustrative } & $\begin{array}{l}\text { Opinion and } \\
\text { example }\end{array}$ & 22 & 1.9 & 0 & 0.0 & 0.0 \\
\hline & & $\begin{array}{l}\text { Opinion and } \\
\text { personal } \\
\text { experience }\end{array}$ & 5 & 0.4 & 0 & 0.0 & 0.0 \\
\hline & & $\begin{array}{l}\text { Tools, } \\
\text { techniques, } \\
\text { methods, } \\
\text { model } \\
\text { applications }\end{array}$ & 148 & 12.7 & 92 & 25.4 & 62.2 \\
\hline & $\begin{array}{l}\text { Applied } \\
\text { concepts }\end{array}$ & $\begin{array}{l}\text { Conceptual } \\
\text { frameworks } \\
\text { and their } \\
\text { application }\end{array}$ & 69 & 5.9 & 41 & 11.3 & 60.3 \\
\hline
\end{tabular}


Information Systems Foundations: The Role of Design Science

\begin{tabular}{|c|c|c|c|c|c|c|c|}
\hline \multirow[t]{12}{*}{ Empirical } & \multirow[t]{2}{*}{ Objects } & $\begin{array}{l}\text { Description of } \\
\text { type or class } \\
\text { of product, } \\
\text { technology, } \\
\text { systems, etc. }\end{array}$ & 39 & 3.3 & 27 & 7.5 & 69.2 \\
\hline & & $\begin{array}{l}\text { Description } \\
\text { of specific } \\
\text { application, } \\
\text { system, etc. }\end{array}$ & 215 & 18.4 & 199 & 55.0 & 92.6 \\
\hline & \multirow{10}{*}{$\begin{array}{l}\text { Events/ } \\
\text { processes }\end{array}$} & Lab experiment & 209 & 17.9 & 0 & 0.0 & 0.0 \\
\hline & & $\begin{array}{l}\text { Field } \\
\text { experiment }\end{array}$ & 19 & 1.6 & 0 & 0.0 & 0.0 \\
\hline & & Field study & 37 & 3.2 & 0 & 0.0 & 0.0 \\
\hline & & $\begin{array}{l}\text { Positivist case } \\
\text { study }\end{array}$ & 64 & 5.5 & 0 & 0.0 & 0.0 \\
\hline & & $\begin{array}{l}\text { Interpretative } \\
\text { case study }\end{array}$ & 37 & 3.2 & 0 & 0.0 & 0.0 \\
\hline & & Action research & 6 & 0.5 & 3 & 0.8 & 50.0 \\
\hline & & Survey & 77 & 6.6 & 0 & 0.0 & 0.0 \\
\hline & & $\begin{array}{l}\text { Development } \\
\text { of DSS } \\
\text { instrument }\end{array}$ & 4 & 0.3 & 0 & 0.0 & 0.0 \\
\hline & & Secondary data & 28 & 2.4 & 0 & 0.0 & 0.0 \\
\hline & & Simulation & 34 & 2.9 & 0 & 0.0 & 0.0 \\
\hline Total & & & 1167 & & 362 & & 31.0 \\
\hline
\end{tabular}

\section{An analysis of DSS design-science research}

In this section, we present the analysis of the papers in the DSS design-science sample. First, some observations are made about the general nature of DSS design science. This is followed by a detailed analysis of the sample using the guidelines proposed by Hevner et al. (2004) — the 'HMPR guidelines'.

\section{'Design science' in DSS design science}

As mentioned in the introduction, the term 'design science' is relatively new to IS research. The definition used to identify DSS design-science research was taken from Hevner et al. (2004:77), who stated that the design-science researcher 'creates and evaluates IT artifacts intended to solve identified organisational problems'. March and Smith (1995) argue that design science must be technology oriented.

In terms of this project, authors do not need to explicitly call their research 'design science' for it to be retrospectively identified as design science. In our 
sample, only six papers (1.7 per cent) mentioned the term design science. This means that the authors of 356 papers (98.3 per cent) either were not aware of design science or did not identify their work as design science. Where authors did identify an overall research strategy, they mostly used terms such as 'description', 'development', 'design' and 'implementation', as shown in Table 1.3. The term 'development' was used in 18 of the 42 papers identified (either on its own or in combination with other terms, including 'implementation', 'design', 'description', 'assessment' and 'validation'). 'Description' was used in 13 papers (on its own or with 'demonstration', 'implementation' and 'development'). 'Design' was utilised in six papers, 'implementation' in four papers and 'demonstration/demonstrate' in three papers.

Table 12.3 Non 'design science' descriptors in DSS design-science research

\begin{tabular}{|l|l|l|}
\cline { 2 - 3 } \multicolumn{1}{c|}{} & Frequency & $\begin{array}{l}\text { Percentage of } \\
\text { sample }\end{array}$ \\
\hline Description & 10 & 2.8 \\
\hline Development & 7 & 1.9 \\
\hline Design & 2 & 0.6 \\
\hline Development and implementation & 2 & 0.6 \\
\hline Design and implementation & 2 & 0.6 \\
\hline Design and development & 2 & 0.6 \\
\hline Exploratory systems development & 2 & 0.6 \\
\hline Action research & 2 & 0.6 \\
\hline Description and demonstration & 1 & 0.6 \\
\hline Description of implementation & 1 & 0.3 \\
\hline Description of development & 1 & 0.3 \\
\hline Design, development and assessment & 1 & 0.3 \\
\hline Development and validation & 1 & 0.3 \\
\hline Systems development & 1 & 0.3 \\
\hline Theory development and implementation & 1 & 0.3 \\
\hline Implementation & 1 & 0.3 \\
\hline Demonstration & 1 & 0.3 \\
\hline Propose-present-demonstrate & 1 & 0.3 \\
\hline Application of model and method & 1 & 0.3 \\
\hline Case study & 1 & 0.3 \\
\hline Decision analysis & 1 & 0.3 \\
\hline Total & 42 & 13.4 \\
\hline
\end{tabular}

To further understand this issue, we examined the citations in the sample of foundational design-science papers. The frequency of citation of these papers is shown in Table 12.4. This confirms the overall impression of the method identification statistics, with only 3 per cent of DSS design-science papers citing these foundational papers. 
Information Systems Foundations: The Role of Design Science

Table 12.4 Design-science citations in DSS research

\begin{tabular}{|l|l|}
\hline Reference & Frequency \\
\hline Simon (1996 or earlier), The Sciences of the Artificial & 3 \\
\hline Walls et al. (1992), ISR & 3 \\
\hline Gero (1990), Al Magazine & 1 \\
\hline Hevner et al. (2004), MISO & 1 \\
\hline March and Smith (1995), DSS & 1 \\
\hline Nunamaker et al. (1991), JMIS & 1 \\
\hline Whyte (1989), Sociological Forum & 1 \\
\hline None & $351(97 \%)$ \\
\hline Total & 362 \\
\hline
\end{tabular}

The literature analysis suggests that the term design science has had little impact in DSS research. Even papers authored by researchers that are leading the design-science movement in IS have not cited design-science reference works or mentioned design science as the method (for example, Berndt et al. 2003). This could be an artefact of journal reviewing practices in which editors and reviewers prefer terms other than design science to describe a paper's overall research strategies.

\section{HMPR guideline 1: the design artefact}

The first HMPR guideline concerns the design artefact. Hevner et al. (2004:Table 1) - following the definitions of March and Smith (1995) — state: 'Design-science research must produce a viable artifact in the form of a construct, a model, a method, or an instantiation.' The coding of the DSS sample yielded 396 artefacts. Thirty-four papers contained significant secondary artefacts in addition to their primary products. The results of the coding are shown in Table 12.5.

Table 12.5 Design artefacts in DSS design-science research (primary and secondary)

\begin{tabular}{|l|l|l|l|l|l|l|l|l|l|l|}
\hline \multirow{2}{*}{ Design artefact } & \multicolumn{2}{l|}{$\mathbf{1 9 9 0 - 9 3}$} & \multicolumn{2}{l|}{$\mathbf{1 9 9 4 - 9 7}$} & \multicolumn{2}{l|}{ 1998-2001 } & \multicolumn{2}{l|}{ 2002-05 } & \multicolumn{2}{l|}{ Total } \\
\cline { 2 - 12 } & (no.) & (\%) & (no.) & (\%) & (no.) & (\%) & (no.) & (\%) & (no.) & (\%) \\
\hline Construct & 0 & 0.0 & 0 & 0.0 & 1 & 1.2 & 1 & 0.9 & 2 & 0.5 \\
\hline Model & 7 & 9.3 & 9 & 7.1 & 5 & 5.9 & 7 & 6.4 & 28 & 7.1 \\
\hline Method & 12 & 16.0 & 34 & 27.0 & 18 & 21.2 & 39 & 35.5 & 103 & 26.0 \\
\hline Instantiation & 56 & 74.7 & 83 & 65.9 & 61 & 71.8 & 63 & 57.3 & 263 & 66.4 \\
\hline Total & $\mathbf{7 5}$ & & $\mathbf{1 2 6}$ & & $\mathbf{8 5}$ & & $\mathbf{1 1 0}$ & & $\mathbf{3 9 6}$ & \\
\hline
\end{tabular}

Clearly, the focus in DSS research over all periods has been on instantiations; they constitute close to two-thirds of all artefacts. High-quality examples of these instantiation artefacts include R-EIS, a repository-based executive information system (Chen 1995), and PUZZLE, a strategic business intelligence system 
(Rouibah and Ould-ali 2002). In a positive sign of a maturing field, however, the development of methods has increased to 35.5 per cent of design artefacts in the most recent period. An example of a high-quality method artefact in this period is the multi-agent design for a DSS in Hall et al. (2005).

\section{HMPR guideline 2: problem relevance}

The second HMPR guideline addresses problem relevance. Hevner et al. (2004:Table 1) define the second guideline, saying that ' $[t]$ he objective of designscience research is to develop technology-based solutions to important and relevant business problems'. Unfortunately, Hevner et al. provide no guidance on how to assess or categorise the 'importance' and 'relevance' constructs.

To operationalise 'importance' in this project, we used the well-accepted concept of a hierarchy of management processes and activities (Anthony 1965). Anthony's framework divides management activities into a hierarchy of importance to the organisation from strategic, through tactical, to operational. Table 12.6 presents the primary focus of the DSS papers over time using Anthony's management activities. The table reveals that the focus has varied a little over time and has been mostly at the operational level (75.7 per cent). Overall, only 10.5 per cent of papers involved artefacts that had a strategic focus or impact.

Table 12.6 The importance of business problems in DSS design-science research

\begin{tabular}{|c|c|c|c|c|c|c|c|c|c|c|}
\hline & \multicolumn{2}{|c|}{ 1990-93 } & \multicolumn{2}{|c|}{ 1994-97 } & \multicolumn{2}{|c|}{$1998-2001$} & \multicolumn{2}{|c|}{ 2002-05 } & \multicolumn{2}{|l|}{ Total } \\
\hline & (no.) & (\%) & (no.) & (\%) & (no.) & (\%) & (no.) & (\%) & (no.) & (\%) \\
\hline Strategic & 3 & 4.2 & 12 & 10.4 & 14 & 18.2 & 9 & 9.2 & 38 & 10.5 \\
\hline Tactical & 14 & 19.4 & 15 & 13.0 & 10 & 13.0 & 11 & 11.2 & 50 & 13.8 \\
\hline Operational & 55 & 76.4 & 88 & 76.5 & 53 & 68.8 & 78 & 79.6 & 274 & 75.7 \\
\hline Total & 72 & & 115 & & 77 & & 98 & & 362 & \\
\hline
\end{tabular}

Further analysis of importance across DSS types revealed that the operational focus was consistently high across personal DSS, GSS, ERAS, IDSS and NSS. In contrast, however, KMS were mostly tactical (71.4 per cent). An example of design-science research with a tactical impact is KNOVA, a knowledge-based DSS for radiologists (Holden and Wilhelmij 1995-96). In concert with the general sample, few KMS were focused on the strategic level. A high-quality exception is an IDSS for strategic alignment in manufacturing (Kathuria et al. 1999).

The relevance of each paper was coded on a scale of high, medium and low. The relevance of DSS design-science research was assessed with respect to two main target audiences: IS practitioners and managerial users. In coding 'relevance', we erred on the generous side - that is, when a decision between categories was difficult, we coded the paper in the category of higher relevance. The result of the coding is shown in Tables 12.7 and 12.8 . 
Information Systems Foundations: The Role of Design Science

Table 12.7 The relevance of DSS design-science research to IS practitioners

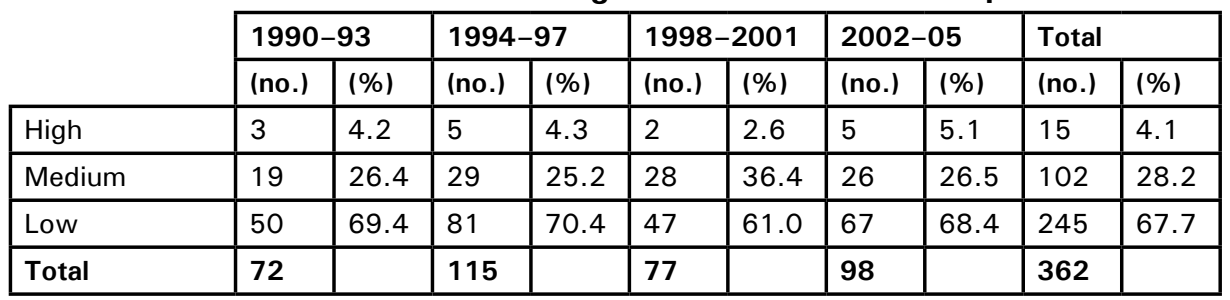

Table 12.7 shows that the relevance scores for IS practitioners have been relatively stable over time. IS practitioner relevance was mostly low in the first period (69.4 per cent in the low-relevance category) and has remained at that level over time. Very few articles (4.1 per cent overall) were rated to be of high relevance to IS practitioners. The story for managerial users in Table 12.8 is a little better, with 23.8 per cent of the papers rated high in managerial relevance and 'only' 41.4 per cent coded as low relevance. The levels of managerial relevance have also been quite stable over time. A further cross-tabulation of IS practitioner relevance against managerial user relevance reveals that only nine of the 362 papers were highly relevant to both groups. The repository-based EIS, R-EIS (Chen 1995), is one example of this high-scoring group.

A further analysis of IS practitioner relevance over the different DSS types showed better relevance ratings for ERAS (53.8 per cent or seven-thirteenths of low relevance), DW systems (25 per cent or one-quarter low relevance) and KMS (28.6 per cent or two-sevenths low relevance) - although it should be noted that the number of papers of these types is quite small. A similar analysis of managerial user relevance revealed that papers on ERAS, KMS and NSS were of greater relevance to managerial users than other types of DSS.

Table 12.8 The relevance of DSS design-science research to managerial users

\begin{tabular}{|l|l|l|l|l|l|l|l|l|l|l|}
\cline { 2 - 13 } \multicolumn{1}{c|}{} & \multicolumn{1}{l|}{$\mathbf{1 9 9 0 - 9 3}$} & \multicolumn{1}{l|}{$1994-97$} & \multicolumn{1}{l|}{$1998-2001$} & \multicolumn{2}{l|}{$2002-05$} & \multicolumn{2}{l|}{ Total } \\
\cline { 2 - 12 } \multicolumn{1}{c|}{} & (no.) & (\%) & (no.) & (\%) & (no.) & (\%) & (no.) & (\%) & (no.) & (\%) \\
\hline High & 14 & 19.4 & 28 & 24.3 & 21 & 27.3 & 23 & 23.5 & 86 & 23.8 \\
\hline Medium & 24 & 33.3 & 33 & 28.7 & 30 & 39.0 & 39 & 39.8 & 126 & 34.8 \\
\hline Low & 34 & 47.2 & 54 & 47.0 & 26 & 33.8 & 36 & 36.7 & 150 & 41.4 \\
\hline Total & $\mathbf{7 2}$ & & $\mathbf{1 1 5}$ & & $\mathbf{7 7}$ & & $\mathbf{9 8}$ & & $\mathbf{3 6 2}$ & \\
\hline
\end{tabular}

\section{HMPR guideline 3: design evaluation}

The third HMPR guideline concerns the evaluation of the design artefacts. Hevner et al. (2004:Table 1) define this guideline, saying, 'The utility, quality, and efficacy of a design artifact must be rigorously demonstrated via wellexecuted evaluation methods.' The coding of the DSS design-science papers for this guideline was based on the evaluation taxonomy presented by Hevner et al. (2004:Table 2). The result of this coding is shown in Table 12.9. 
Table 12.9 Evaluation methods in DSS design-science research

\begin{tabular}{|c|c|c|c|c|c|c|c|c|c|c|c|}
\hline & & \multicolumn{2}{|c|}{ 1990-93 } & \multicolumn{2}{|c|}{ 1994-97 } & \multicolumn{2}{|c|}{$\begin{array}{l}1998- \\
2001\end{array}$} & \multicolumn{2}{|c|}{ 2002-05 } & \multicolumn{2}{|c|}{ Total } \\
\hline & & (no.) & (\%) & (no.) & $(\%)$ & (no.) & $(\%)$ & (no.) & $(\%)$ & (no.) & $(\%)$ \\
\hline \multirow{2}{*}{$\begin{array}{l}\text { Observ- } \\
\text { ational }\end{array}$} & Case study & 6 & 8.3 & 10 & 8.7 & 13 & 16.9 & 13 & 13.3 & 42 & 11.6 \\
\hline & Field study & 1 & 1.4 & 0 & 0.0 & 3 & 3.9 & 3 & 3.1 & 7 & 1.9 \\
\hline \multirow{4}{*}{$\begin{array}{l}\text { Ana- } \\
\text { lytical }\end{array}$} & Static & 0 & 0.0 & 0 & 0.0 & 1 & 1.3 & 0 & 0.0 & 1 & 0.3 \\
\hline & Architecture & 0 & 0.0 & 1 & 0.9 & 0 & 0.0 & 0 & 0.0 & 1 & 0.3 \\
\hline & Optimisation & 0 & 0.0 & 0 & 0.0 & 0 & 0.0 & 0 & 0.0 & 0 & 0.0 \\
\hline & Dynamic & 0 & 0.0 & 0 & 0.0 & 0 & 0.0 & 0 & 0.0 & 0 & 0.0 \\
\hline \multirow[t]{2}{*}{$\begin{array}{l}\text { Experi- } \\
\text { mental }\end{array}$} & $\begin{array}{l}\text { Controlled } \\
\text { experiment }\end{array}$ & 1 & 1.4 & 4 & 3.5 & 5 & 6.5 & 5 & 5.1 & 15 & 4.1 \\
\hline & Simulation & 14 & 19.4 & 17 & 14.8 & 17 & 22.1 & 26 & 26.5 & 74 & 20.4 \\
\hline \multirow[t]{2}{*}{ Testing } & Functional & 0 & 0.0 & 2 & 1.7 & 0 & 0.0 & 2 & 2.0 & 4 & 1.1 \\
\hline & Structural & 0 & 0.0 & 0 & 0.0 & 0 & 0.0 & 1 & 1.0 & 1 & 0.3 \\
\hline \multirow[t]{2}{*}{$\begin{array}{l}\text { Descrip- } \\
\text { tive }\end{array}$} & $\begin{array}{l}\text { Informed } \\
\text { argument }\end{array}$ & 0 & 0.0 & 3 & 2.6 & 2 & 2.6 & 2 & 2.0 & 7 & 1.9 \\
\hline & Scenarios & 13 & 18.1 & 21 & 18.3 & 8 & 10.4 & 15 & 15.3 & 57 & 15.7 \\
\hline None & & 37 & 51.4 & 57 & 49.6 & 28 & 36.4 & 31 & 31.6 & 153 & 42.3 \\
\hline
\end{tabular}

Surprisingly, overall, 42.3 per cent of papers were coded as 'none'. This means that the focus of the paper was the presentation and description of an artefact without any attempt to establish its worth, effectiveness or usefulness. This large proportion of un-evaluated projects is a major problem for DSS design science. Over time, the situation is improvingfrom 51.4 per cent coded as 'none' in the first period to 31.6 per cent in the most recent period. However, 31.6 per cent 'none' is still a very poor result for the discipline. A further analysis of evaluation method against DSS type revealed that 'none' was coded noticeably more often for GSS (54.9 per cent) but less often for IDSS (29.8 per cent).

Of the papers that did include an evaluation of the artefact, three approaches dominated: simulation at 20.4 per cent of the sample, scenarios at 15.7 per cent and case study at 11.6 per cent-with another, controlled experiment, significant at 4.1 per cent. The other evaluation approaches identified by Hevner et al. (2004) are either hardly used or not used at all. Interestingly, only 13.5 per cent of papers evaluated their artefacts in the field. A further analysis of evaluation method by DSS type was performed but was limited to studies where an evaluation was in fact undertaken. This analysis showed that 
- PDSS were evaluated mostly by simulation (37.1 per cent) (for example, Hall et al. 2005), scenarios (28.9 per cent) (for example, Balbo and Pinson 2005) and case studies (18.6 per cent) (for example, Tavana and Banerjee 1995)

- GSS were evaluated mostly by case studies (34.8 per cent) (for example, Dennis et al. 2003; de Vreede and Dickson 2000), ${ }^{1}$ controlled experiments (21.7 per cent) (for example, Zhang et al. 2005) and scenarios (17.4 per cent) (for example, Moreno-Jiminez et al. 2005)

- three of the ERAS papers from the eight evaluated used scenarios (for example, Chen 1995)

- for DW, only one study was evaluated and it used a case study (Sen and Sen 2005)

- IDSS were evaluated mostly by simulation (50 per cent) (for example, Walczak 2001), followed by scenarios (14.2 per cent) (for example, Kathuria et al. 1999)

- KMS (only four papers) were all evaluated by case studies (for example, Holden and Wilhelmij 1995-96)

- NSS (only six papers) were evaluated by scenarios (66.7 per cent) (for example, Kuula 1998) or case studies (33.3 per cent) (for example, Noakes et al. 2005).

The third HMPR guideline stresses rigour in evaluation via well-executed methods. Table 12.9 and the associated analysis by DSS type show the presence or absence of evaluation, but not the quality of evaluation. To analyse the quality of evaluation, each paper that undertook some form of evaluation was first coded for the appropriateness of the evaluation method to the objects of the study and the nature of the artefact. Second, the quality of the execution of the evaluation method in each paper was assessed on a scale of high, medium and low. Like the coding strategy used for Tables 12.7 and 12.8, here, evaluation method choice and execution quality were assessed generously. Tables 12.10 and 12.11 contain these assessments for those DSS papers in which an evaluation method was used.

1 Note that this paper in fact used an action research approach for evaluation but had to be classified as case study because the HMPR guidelines did not include action research as an evaluation method. 
Table 12.10 The choice of evaluation method in DSS design-science research

\begin{tabular}{|l|l|l|l|l|l|l|l|l|l|l|}
\cline { 2 - 12 } \multicolumn{1}{c|}{} & \multicolumn{2}{l|}{$\mathbf{1 9 9 0 - 9 3}$} & \multicolumn{1}{l|}{$1994-97$} & \multicolumn{2}{l|}{$1998-2001$} & \multicolumn{2}{l|}{$2002-05$} & \multicolumn{2}{l|}{ Total } \\
\cline { 2 - 12 } \multicolumn{1}{c|}{} & (no.) & (\%) & (no.) & (\%) & (no.) & (\%) & (no.) & (\%) & (no.) & (\%) \\
\hline $\begin{array}{l}\text { Highly } \\
\text { appropriate }\end{array}$ & 16 & 45.7 & 25 & 43.1 & 36 & 73.5 & 38 & 56.7 & 115 & 55.0 \\
\hline Adequate & 18 & 51.4 & 32 & 55.2 & 12 & 24.5 & 28 & 41.8 & 90 & 43.1 \\
\hline Poor & 1 & 2.9 & 1 & 1.7 & 1 & 2.0 & 1 & 1.5 & 4 & 1.9 \\
\hline Total & $\mathbf{3 5}$ & & $\mathbf{5 8}$ & & $\mathbf{4 9}$ & & $\mathbf{6 7}$ & & $\mathbf{2 0 9}$ & \\
\hline
\end{tabular}

In each era, when evaluation did occur, the level of appropriateness of the evaluation method choice was at least 'adequate'. This indicates that researchers who evaluate artefacts are making reasonable choices in terms of method. Over time, the quality of the choice of evaluation method has been a little variable, but there is no significant trend in the coding.

Table 12.11 The quality of evaluation execution in DSS design-science research

\begin{tabular}{|c|c|c|c|c|c|c|c|c|c|c|}
\hline & \multicolumn{2}{|c|}{ 1990-93 } & \multicolumn{2}{|c|}{ 1994-97 } & \multicolumn{2}{|c|}{$1998-2001$} & \multicolumn{2}{|c|}{ 2002-05 } & \multicolumn{2}{|c|}{ Total } \\
\hline & (no.) & (\%) & (no.) & (\%) & (no.) & (\%) & (no.) & (\%) & (no.) & (\%) \\
\hline High & 5 & 14.3 & 16 & 27.6 & 13 & 26.5 & 23 & 34.3 & 57 & 27.3 \\
\hline Medium & 17 & 48.6 & 24 & 41.4 & 26 & 53.1 & 34 & 50.7 & 101 & 48.3 \\
\hline Low & 13 & 37.1 & 18 & 31.0 & 10 & 20.4 & 10 & 14.9 & 51 & 24.4 \\
\hline Total & 35 & & 58 & & 49 & & 67 & & 209 & \\
\hline
\end{tabular}

Table 12.11 shows that in each era, when evaluation was conducted, the quality of evaluation was mostly medium to high. This indicates that those researchers are doing a reasonable job in conducting the evaluation. Further, the proportion of low-quality execution has steadily decreased - from 37.1 per cent in 1990-93 to only 14.9 per cent in $2002-05$.

The overall picture in relation to evaluation is that, surprisingly, more than 40 per cent of DSS design-science projects do not undertake formal evaluation of the artefacts. When artefact evaluation is performed, researchers generally make an appropriate choice of method. Further, the quality of the execution of evaluation is steadily, and significantly, improving.

\section{HMPR guideline 4: research contributions}

The fourth HMPR guideline concerns the research contributions of design science. Hevner et al. (2004:Table 1) define this guideline by saying that ' $[\mathrm{e}] \mathrm{ffective}$ design-science research must provide clear and verifiable contributions in the areas of the design artifact, design foundations, and/or design methodologies'. Each paper in the DSS sample was examined for its primary research contribution according to the HMPR definition. Secondary contributions were also recorded 
where they occurred. Among the 362 papers, the design artefact was the primary research contribution in 360 cases, with only one paper having design foundations and one having design methodologies as their primary research contribution. Only eight papers had a secondary research contribution: one in the design artefact, six in design foundations and one contribution to design methodologies.

There were a number of examples of high-quality research contribution through a design artefact. These included a repository-based executive information system (Chen 1995), a strategic business intelligence system (Rouibah and Ouldali 2002) and a knowledge-based DSS for radiologists (Holden and Wilhelmij 1995-96). Two notable contributions to design foundations were a design theory for systems that support emergent knowledge processes (Markus et al. 2002) and a groupware-based business process re-engineering process (Dennis et al. 2003). An example of a high-quality contribution to evaluation methodologies is DeSanctis et al. (1994), who have developed a method for conducting a preliminary evaluation of an EMS. In particular, their method assesses the match between user and designer perspectives on system interface, functionality and holistic attributes.

\section{HMPR guideline 5: research rigour}

The fifth HMPR guideline concerns the rigour of design-science research. Hevner et al. (2004:Table 1) define this guideline, saying: 'Design-science research relies upon the application of rigorous methods in both the construction and evaluation of the design artifact.'

We operationalised this guideline using two constructs: the rigour of the theoretical foundations of the research and the rigour of the research methodology. Each construct was coded on a scale of strong, adequate or weak. As with other HMPR guidelines, here, the coding was generous with respect to assessments at category boundaries.

The rigour of theory foundations was coded by considering the use of appropriate reference theory - and in particular, argument as to why the reference theory was appropriate. The effective use of theory in evaluation and the discussion were coded highly, as was consideration of the limitations or weaknesses of the theory foundations. The result of the coding for the rigour of theory foundations is shown in Table 12.12. More than 80 per cent of papers were coded as either adequate or strong. This has been fairly consistent over time and represents a good result for the DSS discipline. A cross-tabulation of the rigour of theory foundations with DSS type found that the data in Table 12.12 were fairly consistent across DSS type. 
Table 12.12 The rigour of the theoretical foundations of DSS designscience research

\begin{tabular}{|c|c|c|c|c|c|c|c|c|c|c|}
\hline & \multicolumn{2}{|c|}{ 1990-93 } & \multicolumn{2}{|c|}{ 1994-97 } & \multicolumn{2}{|c|}{ 1998-2001 } & \multicolumn{2}{|c|}{ 2002-05 } & \multicolumn{2}{|l|}{ Total } \\
\hline & (no.) & (\%) & (no.) & (\%) & (no.) & (\%) & (no.) & (\%) & (no.) & (\%) \\
\hline Strong & 20 & 27.8 & 41 & 35.7 & 26 & 33.8 & 38 & 38.8 & 125 & 34.5 \\
\hline Adequate & 38 & 52.8 & 47 & 40.9 & 42 & 54.5 & 46 & 46.9 & 173 & 47.8 \\
\hline Weak & 14 & 19.4 & 27 & 23.5 & 9 & 11.7 & 14 & 14.3 & 64 & 17.7 \\
\hline Total & 72 & & 115 & & 77 & & 98 & & 362 & \\
\hline
\end{tabular}

The result of the coding of the rigour of research methodologies in the sample is shown in Table 12.13. The results are extremely disappointing, with 75 per cent of papers in the weak category and only 3.3 per cent coded as strong. Most of the papers in the 'weak' set did not mention research method and design at all. The time trend in the sample is for the less rigorous category to decrease substantially over time - a positive result for the field. Unfortunately, the improvement has been in the adequate and not in the strong category.

Table 12.13 The rigour of the research methodologies of DSS designscience research

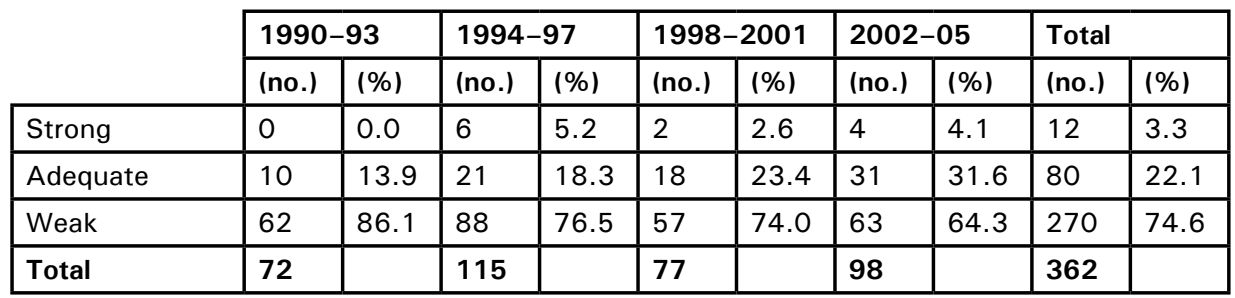

Table 12.14 contains a cross-tabulation of the rigour of the theoretical foundations against the rigour of the research methodologies. It reveals a strong association between the constructs (a correlation of 0.408, which is significant at the 0.1 per cent level). Also, the table reveals the direction of the association. In the 64 design-science DSS cases in which the theoretical foundations are weak, all 64 are weak in their research methodologies. This means that DSS design-science researchers who are not rigorous with their theoretical foundations pay little attention to research methodology issues.

Table 12.14 Theoretical foundations versus research methodologies

\begin{tabular}{|l|l|l|l|l|l|l|l|l|}
\cline { 2 - 11 } \multicolumn{1}{c|}{} & \multicolumn{4}{l}{ Theoretical foundations } \\
\hline \multirow{2}{*}{ Research methodologies } & \multicolumn{2}{l}{ Strong } & \multicolumn{2}{l|}{ Adequate } & \multicolumn{2}{l|}{ Weak } & \multicolumn{2}{l|}{ Total } \\
\cline { 2 - 11 } & (no.) & (\%) & (no.) & (\%) & (no.) & (\%) & (no.) & (\%) \\
\hline Strong & 10 & 7.9 & 2 & 1.2 & 0 & 0.0 & 12 & 3.3 \\
\hline Adequate & 52 & 41.3 & 28 & 16.3 & 0 & 0.0 & 80 & 22.1 \\
\hline Weak & 64 & 50.8 & 142 & 82.6 & 64 & 100.0 & 270 & 74.6 \\
\hline Total & $\mathbf{1 2 6}$ & & $\mathbf{1 7 2}$ & & $\mathbf{6 4}$ & & $\mathbf{3 6 2}$ & \\
\hline
\end{tabular}




\section{HMPR guideline 6: design as a search process}

The sixth HMPR guideline concerns the iterative search process that is characteristic of high-quality design. Hevner et al. (2004:Table 1) define this guideline as '[t]he search for an effective artifact [which] requires utilizing available means to reach desired ends while satisfying laws in the problem environment'.

Thirty-seven papers (10.2 per cent of the sample) decomposed the design problem into sub-problems, 23 papers (6.4 per cent of the sample) displayed iteration from the sub-problem solution to the overall problem solution and 10 papers (2.8 per cent of the sample) used 'satisficing' to decide on the solution convergence point. This analysis shows little support for an evident search process in DSS design-science research.

\section{HMPR guideline 7: communication of research}

The seventh, and final, HMPR guideline concerns the communication of research. Hevner et al. (2004:Table 1) define this guideline by saying: 'Designscience research must be presented effectively both to technology-oriented as well as management-oriented audiences.'

The effectiveness of communication was coded on a scale of high, medium and low, with the 'generous' approach of the coding of other constructs. Both coders have significant technical and managerial experience. The result of the coding is shown in Tables 12.15 and 12.16.

Table 12.15 The effectiveness of technology-oriented communication in DSS design-science research

\begin{tabular}{|l|l|l|l|l|l|l|l|l|l|l|}
\cline { 2 - 12 } \multicolumn{1}{c|}{} & \multicolumn{1}{c|}{$\mathbf{1 9 9 0 - 9 3}$} & \multicolumn{1}{l|}{$1994-\mathbf{9 7}$} & \multicolumn{2}{l|}{ 1998-2001 } & \multicolumn{2}{l|}{ 2002-05 } & \multicolumn{2}{l|}{ Total } \\
\cline { 2 - 12 } \multicolumn{1}{c|}{} & (no.) & (\%) & (no.) & (\%) & (no.) & (\%) & (no.) & (\%) & (no.) & (\%) \\
\hline High & 17 & 23.6 & 29 & 25.2 & 28 & 36.4 & 41 & 41.8 & 115 & 31.8 \\
\hline Medium & 43 & 59.7 & 61 & 53.0 & 41 & 53.2 & 48 & 49.0 & 193 & 53.3 \\
\hline Low & 12 & 16.7 & 25 & 21.7 & 8 & 10.4 & 9 & 9.2 & 54 & 14.9 \\
\hline Total & $\mathbf{7 2}$ & & $\mathbf{1 1 5}$ & & $\mathbf{7 7}$ & & $\mathbf{9 8}$ & & $\mathbf{3 6 2}$ & \\
\hline
\end{tabular}

Table 12.16 The effectiveness of management-oriented communication in DSS design-science research

\begin{tabular}{|l|l|l|l|l|l|l|l|l|l|l|}
\cline { 2 - 12 } \multicolumn{1}{c|}{} & \multicolumn{2}{l|}{$1990-93$} & \multicolumn{2}{l|}{$1994-97$} & \multicolumn{2}{l|}{ 1998-2001 } & \multicolumn{2}{l|}{ 2002-05 } & \multicolumn{2}{l|}{ Total } \\
\cline { 2 - 12 } \multicolumn{1}{c|}{} & (no.) & $\mathbf{( \% )}$ & (no.) & (\%) & (no.) & (\%) & (no.) & (\%) & (no.) & (\%) \\
\hline High & 0 & 0.0 & 2 & 1.7 & 3 & 3.9 & 0 & 0.0 & 5 & 1.4 \\
\hline Medium & 10 & 13.9 & 8 & 7.0 & 14 & 18.2 & 16 & 16.3 & 48 & 13.3 \\
\hline Low & 62 & 86.1 & 105 & 91.3 & 60 & 77.9 & 82 & 83.7 & 309 & 85.4 \\
\hline Total & $\mathbf{7 2}$ & & $\mathbf{1 1 5}$ & & $\mathbf{7 7}$ & & $\mathbf{9 8}$ & & $\mathbf{3 6 2}$ & \\
\hline
\end{tabular}


The effectiveness of technical communication was reasonable, with 85.1 per cent of papers coded as medium or high. Further, the proportion of papers with high effectiveness increases with each period. The effectiveness of management communication is the reverse of technical communication, with 85.4 per cent of DSS papers coded as low effectiveness. Further, there is no significant improvement in the percentage of 'low' papers over time. Unfortunately, only 1.4 per cent of papers have high effectiveness in managerial communication.

The picture that emerges in Tables 12.15 and 12.16 is of a discipline with a strong technical focus but one whose papers are unlikely to influence managerial activities. Table 12.16 goes a long way towards explaining the perceived lack of relevance in DSS (and IS) research. Perhaps the table is a reflection of the nature of academic journals, in which the rigour of theory base, design and execution is rewarded by publication. The table is also influenced by the nature of the DSS design-science sample. There are no premier professional journals in the sample as the object of this chapter is to assess the quality of DSS design-science research. Had the Harvard Business Review, Sloan Management Review and MIS Quarterly Executive been in the sample, the statistics for the effectiveness of managerial communication could have been more encouraging. On the other hand, we suspect the number of DSS articles in these premier professional journals could be small.

\section{Summary of the HPMR guideline-based analysis}

Using the HPMR guidelines has provided an evidence-based understanding of the nature of DSS design-science research. The analysis shows that design science as a term has had little usage in DSS research and the current debate on design science is yet to impact on published DSS research. Despite this, design science is the strategy of 31 per cent of published DSS research since 1990. The focus in DSS design-science research over all periods has been on instantiations; they constitute close to two-thirds of all research artefacts. Methods are about onequarter of DSS design-science artefacts. The 'artefact' is the major contribution of most DSS design-science papers, with few making design foundations or methodology contributions. DSS design science addresses problems at the lowest level of managerial impact; operational management support is the focus of 75 per cent of papers. The assessment of relevance shows that two-thirds of papers are of low relevance to IS practitioners. The assessment of relevance to managers is significantly better. Evaluation is a major problem area for DSS design science, with 42 per cent of papers not undertaking any form of evaluation. The rigour of the theory foundations of DSS design science is reasonable, but many papers do not explicitly address research design. In terms of the communication of results, the analysis shows a discipline with a strong technical focus but also one whose papers are unlikely to influence managerial activities. 


\section{Strategies for improving DSS design-science research}

The analysis in the previous section provides a basis for considering how to improve the quality and impact of DSS design-science research. A word of caution is warranted before proceeding. Our aim is to identify major areas that can be improved in DSS design-science research. This identification can paint an overly negative impression of the field, which is not our intention. Further, the standard of IS research has improved significantly since 1990 and an assessment of older research from a 2008 perspective could be biased. It is important to remember that DSS design-science research has progressed in the 16 years of the sample period without the assistance of an agreed set of guidelines for what constitutes quality in design-science research. Nevertheless, the analysis in the previous section has highlighted four major areas that need serious attention. The areas identified overlap considerably and represent different levels of abstraction about the problems of DSS design-science research.

\section{Evaluation}

Evaluation is the biggest weakness in DSS design-science research. The focus of many papers is the description of an instantiation without any attempt at evaluation. The presence of rigorous and convincing evaluation is an important separator of consulting, professional design and design research. Some form of convincing evaluation should be mandatory for design-science research.

The analysis in this chapter shows that those researchers who have performed some form of evaluation usually choose an appropriate strategy but the quality of the execution of the evaluation needs significant improvement.

There is also a need to broaden the base of evaluation methods and techniques. Three methods currently dominate DSS research: simulation, scenarios and case studies - with experiments also significant. This is a very narrow methodological base. Other evaluation approaches in Hevner et al. (2004:Table 2 ) could be relevant and methods not in this table should be considered. These could include qualitative methods such as focus groups.

\section{Research foundations and methodologies}

The next major area of concern is with the theoretical foundation and research methodology of DSS design science. These are surprising concerns and are not explained by an averaging effect where, for example, poor foundations early in the sample are offset by strong foundations in papers later in the sample. 
The most disappointing result in the analysis was that 75 per cent of papers were identified as being 'weak' with respect to research methods. Most of these papers did not mention research design at all. While the rigour of research methods was low, the effectiveness of managerial communication (Guideline 7) was even worse, with 85 per cent of papers coded in the poorest category. This implies that there is no trade-off between rigour and relevance in DSS designscience research.

We believe that researchers should focus on improving the rigour of all aspects of design-science research. It is the rigour of academic research that is most valued by practitioners. A greater focus on quality in research foundations and methods will also help build to a cumulative tradition in DSS design-science. We noticed during the coding, principally through the citation of DSS work, that although not covered by the HMPR guidelines, there is no general sense of published research building on previous DSS design-science projects.

\section{Strategic focus}

The analysis under Guideline 2-problem relevance-shows that 75 per cent of DSS design-science research has been focused on operational management problems. If DSS design science is going to have a major impact on the way managers work and make decisions, researchers need to increase the organisational importance of the tasks that are targeted. This is particularly important as the business intelligence movement has raised the visibility of, and demand for, decision support by senior managers and executives.

\section{Theorising}

The final major area of DSS design-science that we believe needs significant improvement is the level and quantity of theorising in published papers. This finding builds on the previous discussion regarding research foundations and methodologies. It is not related to a particular HMPR guideline but emerges from the overall analysis in section three.

We need to move beyond an instantiation as the primary focus in DSS design science. Gregor and Jones (2007) divide design artefacts into material or abstract artefacts. They argue that the abstract artefacts - constructs, models and methods - are theory or components of theory. One of the strongest findings in section three is that 66 per cent of design artefacts in DSS research are instantiations. It is clear that the DSS field needs to urgently emphasise theory and theorising in design-science projects. A key aspect of this improvement should be the explicit consideration of IS design theory in manuscripts (Walls et al. 1992; Gregor and Jones 2007). 


\section{Comments on the Hevner, March, Park and Ram guidelines}

It is clear from the Thomson ISI citation count that the HMPR guidelines will be a major reference work for IS design-science researchers. In this section, we reflect on the effectiveness of the guidelines in assessing a large sample of design-science papers.

In general, the guidelines were relatively easy to apply. The major difficulty in the design of the content analysis was the lack of definition of the constructs for some guidelines. As described above, we operationalised these opinion-based constructs on three-point scales. This proved to be an effective approach to coding and there were few disagreements between the coders. We did find that it was important to keep rereading Hevner et al. (2004) during the coding process in order to remain calibrated to their definitions, constructs and meanings.

It was very difficult to assess Guideline 6-which relates to design as a search process - from the published papers. By their nature, journal papers are written in a linear style. Often the research design and the project description can appear more ordered, and more structured, than is in fact the case. This is not a criticism of these papers; it is an artefact of the publishing process. It does, however, create a problem for the assessment of the iterative search process of a piece of design-science research. As a result, the assessment of papers for HMPR Guideline 6 is difficult or biased unless the search process is explicitly addressed by the authors.

In response to one of the concerns in the previous section, we believe that Guideline 4-which relates to the research contributions of a paper-could be broadened to include an explicit contribution to theory.

Hevner et al. (2004:82) state: 'Following Klein and Myers (1999) we advise against mandatory or rote use of the guidelines.' Following the analysis of DSS design science, we believe that some of the guidelines should be mandatory - namely, Guideline 1, the design artefact; Guideline 2, problem relevance; Guideline 3, evaluation; and Guideline 5, research rigour.

Notwithstanding these concerns, using the HMPR guidelines to analyse a large set of DSS design-science papers did provide a clear idea of the state of the field. More importantly, they provide a clear idea of the areas that need significant improvement. 


\section{Concluding comments}

This study is subject to a number of limitations. The first concerns the representativeness of the sample. The use of the Alavi and Carlson categories as the filters for the DSS design-science sample could underestimate the sample size as the coding was based on the focus or dominant method of the paper. Some papers that were coded as experiments could really have been design science but the published papers paid cursory attention to artefact construction. In particular, the journal reviewing practices early in the sample could have encouraged this style of write-up. Fortunately, the sample is large and this effect should be diluted.

The second limitation concerns the subjective nature of some of the coding. This is inevitable when interpreting guidelines that do not have well-defined constructs. We believe that researchers with considerable experience in DSS research and design science who used our protocol on our sample would generate similar data.

This study shows that design science is an important part - perhaps the major part - of DSS research. The lessons learned from the application of the HMPR guidelines should help to significantly improve DSS research. Our further research into the nature of DSS design-science research includes the use of the HMPR guidelines to develop a 'balanced scorecard' that will provide a quality measure of a piece of design-science research. A second strand of further research will attempt to distil the general design theories that have been used for DSS design science.

The stakes are high for DSS design science. If we get design science right, if it is relevant and rigorous, we will have increased influence in industry and the profession - much like what occurs in medicine. If we get it wrong, the disconnect between academe and practice will be amplified.

\section{References}

Alavi, M. and Carlson, P. 1992, 'A review of MIS research and disciplinary development', Journal of Management Information Systems, vol. 8, no. 4, pp. 45-62.

Anthony, R. N. 1965, Planning and Control Systems: A framework for analysis, Graduate School of Business Administration, Harvard University, Cambridge, Mass. 
Arnott, D. 2004, 'Decision support systems evolution: framework, case study and research agenda', European Journal of Information Systems, vol. 13, no. 4, pp. 247-59.

Arnott, D. 2006, 'Cognitive biases and decision support systems development: a design science approach', Information Systems Journal, vol. 16, no. 1, pp. $55-78$.

Arnott, D. 2008, 'Personal decision support systems', in F. Burstein and C. W. Holsapple (eds), Decision Support Systems Handbook, Springer-Verlag, Berlin, pp. 127-50.

Arnott, D. and Pervan, G. 2005, 'A critical analysis of decision support systems research', Journal of Information Technology, vol. 20, no. 2, pp. 67-87.

Arnott, D. and Pervan, G. 2008, 'Eight key issues for the decision support systems discipline', Decision Support Systems, vol. 44, pp. 657-72.

Balbo, F. and Pinson, S. 2005, 'Dynamic modeling of a disturbance in a multiagent system for traffic regulation', Decision Support Systems, vol. 41, pp. $131-46$.

Benbasat, I. and Nault, B. 1990, 'An evaluation of empirical research in managerial support systems', Decision Support Systems, vol. 6, no. 3, pp. 203-26.

Benbasat, I. and Zmud, R. W. 1999, 'Empirical research in information systems: the question of relevance', MIS Quarterly, vol. 23, no. 1, pp. 3-16.

Benbasat, I. and Zmud, R. W. 2003, 'The identity crisis within the IS discipline: defining and communicating the discipline's core properties', MIS Quarterly, vol. 27, no. 2, pp. 183-94.

Berndt, D. J., Hevner, A. R. and Studnicki, J. 2003, 'The catch datawarehouse: support for community health care decision-making', Decision Support Systems, vol. 35, no. 3, pp. 367-84.

Burstein, F. and Carlsson, S. A. 2008, 'Decision support through knowledge management', in F. Burstein and C. W. Holsapple (eds), Decision Support Systems Handbook, Springer-Verlag, Berlin, pp. 103-20.

Chen, M. 1995, 'A model-driven approach to accessing managerial information: the development of a repository-based executive information system', Journal of Management Information Systems, vol. 11, no. 4, pp. 33-63.

Chen, W. S. and Hirschheim, R. 2004, 'A paradigmatic and methodological examination of information systems research from 1991 to 2001', Information Systems Journal, vol. 14, no. 3, pp. 197-235. 
Dennis, A. R., Carte, T. A. and Kelly, G. G. 2003, 'Breaking the rules: success and failure in groupware-supported business process reengineering', Decision Support Systems, vol. 36, pp. 31-47.

Dennis, A. R., George, J. F., Jessup, L. M., Nunamaker, J. F. jr and Vogel, D. R. 1988, 'Information technology to support electronic meetings', MIS Quarterly, December, pp. 591-624.

DeSanctis, G., Snyder, J. and Poole, M. S. 1994, 'The meaning of the interface: a functional and holistic evaluation of a meeting software system', Decision Support Systems, vol. 11, pp. 319-35.

de Vreede, G.-J. and Dickson, G. 2000, 'Using GSS to design organizational processes and information systems: an action research study on collaborative business engineering', Group Decision and Negotiation, vol. 9, pp. 161-83.

Eom, S. B. 1995, 'Decision support systems research: reference disciplines and a cumulative tradition', Omega: The International Journal of Management Science, vol. 23, no. 5, pp. 511-23.

Eom, S. B. 1996, 'Mapping the intellectual structure of research in decision support systems through author cocitation analysis (1971-1993)', Decision Support Systems, vol. 16, no. 4, pp. 315-38.

Eom, S. B. 1999, 'Decision support systems research: current state and trends', Industrial Management and Data Systems, vol. 99, no. 5, pp. 213-20.

Eom, H. B. and Lee, S. M. 1990, 'A survey of decision support system applications (1971-1988)', Interfaces, vol. 20, no. 3, pp. 65-79.

Eom, S.B. and Lee, S. M. 1993, 'Leading universities and most influential contributors in DSS research: a citation analysis', Decision Support Systems, vol. 9, no. 3, pp. 237-44.

Gero, J. S. 1990, 'Design prototypes: a knowledge representation schema for design', AI Magazine, vol. 11, no. 4, pp. 26-36.

Gillenson, M. L. and Stutz, J. D. 1991, 'Academic issues in MIS: journals and books', MIS Quarterly, vol. 15, no. 4, pp. 447-52.

Gregor, S. and Jones, D. 2007, 'The anatomy of a design theory', Journal of the Association for Information Systems, vol. 8, no. 5, pp. 312-35.

Hall, D., Guo, Y., Davis, R. A. and Cegielski, C. 2005, 'Extending unbounded systems thinking with agent-oriented modelling: conceptualizing a multiple perspective decision-making support system', Decision Support Systems, vol. 41, pp. 279-95. 
Hardgrave, B. C. and Walstrom, K. A. 1997, 'Forums for MIS scholars', Communications of the ACM, vol. 40, no. 11, pp. 119-24.

Hevner, A. R., March, S. T., Park, J. and Ram, S. 2004, 'Design science in information systems research', MIS Quarterly, vol. 28, no. 1, pp. 75-106.

Hirschheim, R. 1992, 'Information systems epistemology: a historical perspective', in R. Galliers (ed.), Information Systems Research: Issues, methods and practical guidelines, Blackwell Scientific Publications, Oxford, pp. 28-60.

Holden, T. and Wilhelmij, P. 1995-96, 'Improved decision making through better integration of human resource and business process factors in a hospital situation', Journal of Management Information Systems, vol. 12, no. 3, pp. $21-41$.

Holsapple, C., Johnson, L., Manakyan, H. and Tanner, J. 1994, 'Business computing research journals: a normalized citation analysis', Journal of Management Information Systems, vol. 11, no. 1, pp. 131-40.

Huber, G. P. 1984, 'Issues in the design of group decision support systems', MIS Quarterly, vol. 8, no. 3, pp. 195-204.

Kaplan, R. S. and Norton, D. P. 1996, The Balanced Scorecard: Translating strategy into action, Harvard Business School Press, Cambridge, Mass.

Katerattanakul, P. and Han, B. 2003, 'Are European IS journals under-rated? An answer based on citation analysis', European Journal of Information Systems, vol. 12, pp. 60-71.

Kathuria, R., Anandarajan, M. and Igbaria, M. 1999, 'Linking IT applications with manufacturing strategy: an intelligent decision support system approach', Decision Sciences, vol. 30, no. 4, pp. 959-91.

Keen, P. G. W. and Gambino, T. J. 1983, 'Building a decision support system: the mythical man-month revisited', in J. L. Bennett (ed.), Building Decision Support Systems, Addison-Wesley, Reading, Mass., 133-72.

Keen, P. G. W. and Scott Morton, M. S. 1978, Decision Support Systems: An organisational perspective, Addison-Wesley, Reading, Mass.

Klein, H. K. and Myers, M. D. 1999, 'A set of principles for conducting and evaluating interpretive field studies in information systems', MIS Quarterly, vol. 23, no. 1, pp. 67-94. 
Kuula, M. 1998, 'Solving intra-company conflicts using the RAMONAinteractive negotiation support system', Group Decision and Negotiation, vol. 7, pp. 447-64.

Land, F. 1992, 'The information systems domain', in R. D. Galliers (ed.), Information Systems Research: Issues, methods and practical guidelines, Blackwell Scientific, Oxford, pp. 6-13.

Lee, A. 2001, 'Editor's comments', MIS Quarterly, vol. 25, no. 1, pp. iii-vii.

March, S. and Smith, G. F. 1995, 'Design \& natural science research on information technology', Decision Support Systems, vol. 15, no. 4, pp. 251-66.

Markus, M. L., Majchrzak, A. and Gasser, L. 2002, 'A design theory for systems that support emergent knowledge processes', MIS Quarterly, vol. 26, no. 3, pp. 179-212.

Meador, C. L. and Ness, D. N. 1974, 'Decision support systems: an application to corporate planning', Sloan Management Review, vol. 15, no. 2, pp. 51-68.

Moreno-Jiminez, J. M., Joven, J. A., Pirla, A. R. and Lanuza, A. T. 2005, 'A spreadsheet module for consistent consensus building in AHP decision making', Group Decision and Negotiation, vol. 14, pp. 89-108.

Mylonopoulos, N. A. and Theoharakis, V. 2001, 'On-site: global perceptions of IS journals', Communications of the ACM, vol. 44, no. 9, pp. 29-33.

Nelson, R. R., Todd, P. A. and Wixom, B. H. 2005, 'Antecedents of information and system quality: an empirical examination within the context of data warehousing', Journal of Management Information Systems, vol. 21, no. 4, pp. 199-235.

Noakes, D. J., Fang, L., Hipel, K. W. and Kilgour, D. M. 2005, 'The Pacific salmon treaty: a century of debate and an uncertain future', Group Decision and Negotiation, vol. 14, pp. 501-22.

Nunamaker, J. F. jr, Chen, M. and Purdin, T. D. M. 1991, 'Systems development in information systems research', Journal of Management Information Systems, vol. 7, no. 3, pp. 89-106.

Orlikowski, W. J. and Iacono, C. S. 2001, 'Research commentary: desperately seeking the "IT" in IT research-a call for theorizing the IT artifact', Information Systems Research, vol. 12, no. 2, pp. 121-34.

Osareh, F. 1996, 'Bibliometrics, citation analysis and co-citation analysis: a review of literature I', Libri, vol. 46, pp. 149-58. 
Pervan, G. P. 1998, ‘A review of research in group support systems: leaders, approaches and directions', Decision Support Systems, vol. 23, no. 2, pp. 149-59.

Pervan, G. P. and Atkinson, D. J. 1995, 'GDSS research: an overview and historical analysis', Group Decision and Negotiation, vol. 4, no. 6, pp. 475-85.

Rangaswamy, A. and Shell, G. R. 1997, 'Using computers to realize joint gains in negotiations: toward an "electronic bargaining table"', Management Science, vol. 43, no. 8, pp. 1147-63.

Rouibah, K. and Ould-ali, S. 2002, 'PUZZLE: a concept and prototype for linking business intelligence to business strategy', Journal of Strategic Information Systems, vol. 11, no. 2, pp. 133-52.

Sen, R. and Sen, T. K. 2005, 'A meta-modeling approach to designing e-warehousing systems', Journal of Organizational Computing and Electronic Commerce, vol. 15, no. 4, pp. 295-316.

Simon, H. A. 1996, The Sciences of the Artificial, Third edition, MIT Press, Cambridge, Mass.

Tavana, M. and Banerjee, S. 1995, 'Strategic assessment model (SAM): a multiple criteria decision support system for evaluation of strategic alternatives', Decision Sciences, vol. 26, no. 1, pp. 119-43.

Turban, E., Aronson, J. E. and Liang, T.-P. 2005, Decision Support Systems and Intelligent Systems, Seventh edition, Pearson Education, Upper Saddle River, NJ.

Walczak, S. 2001, 'An empirical analysis of data requirements for financial forecasting with neural networks', Journal of Management Information Systems, vol. 17, no. 4, pp. 203-22.

Walls, J. G., Widmeyer, G. R. and El Sawy, O. A. 1992, 'Building an information systems design theory for vigilant EIS', Information Systems Research, vol. 3, no. 1 (March), pp. 36-59.

Walstrom, K. A., Hardgrave, B. C. and Wilson, R. L. 1995, 'Forums for management information systems scholars', Communications of the ACM, vol. 38, no. 3, pp. 93-107.

Watson, H. J. 2001, 'Recent developments in data warehousing', Communications of the Association for Information Systems, vol. 8, pp. 1-25.

Weber, R. P. 1990, Basic Content Analysis, Second edition, Sage, Newbury Park, Calif. 
Webster, J. and Watson, R. T. 2002, 'Analyzing the past to prepare for the future: writing a literature review', MIS Quarterly, vol. 26, no. 2, pp. xiii-xxiii.

Whitman, M. E., Hendrickson, A. R. and Townsend, A. M. 1999, 'Research commentary: academic rewards for teaching, research and service: data and discourse', Information Systems Research, vol. 10, no. 2, pp. 99-109.

Whyte, W. F. 1989, 'Advancing Scientific Knowledge Through Participatory Action Research', Sociological Forum, vol. 4, no. 3, pp. 367-385.

Zhang, P., Sun, J. and Chen, H. 2005, 'Frame-based argumentation for group decision task generation and identification', Decision Support Systems, vol. 39, pp. 643-59.

\section{Appendix 12.1}

\section{Article coding protocol}

\section{Guideline 1: the design artefact}

1.1 Type of artefact $\quad$ 1. Construct $\quad$ 2. Model $\quad 3$. Method $\quad$ 4. Instantiation

1.2 What was the artefact?

\section{Guideline 2: problem relevance}

\begin{tabular}{llll}
\hline 2.1 Importance of business problem & 1. Strategic & 2. Tactical & 3. Operational \\
2.2 Relevance to IS practitioners & 1. High & 2. Medium & 3. Low \\
2.3 Relevance to managerial users & 1. High & 2. Medium & 3. Low
\end{tabular}

\section{Guideline 3: design evaluation}

3.1 Type of evaluation
Observational 1. Case study
2. Field study
Analytical 3. Static 4. Architecture
4. Architectu
5. Optimisation
6. Dynamic
Experimental
10. Structural (white box)
Testing
9. Functional (black box)
Descriptive
11. Informed argument
12. Scenarios
13. None

3.2 Choice of evaluation method

1. Highly appropriate

2. Adequate

3. Poor choice

3.3 Quality of execution of evaluation

1. High

2. Medium

3. Low

\section{Guideline 4: research contributions}

$\begin{array}{llll}4.1 \text { Contribution area } & \text { 1. The design artefact } & \text { 2. Foundations } & \text { 3. Design methodologies }\end{array}$

\section{Guideline 5: research rigour}

5.1 Theoretical foundations

5.2 Research methodologies
1. Strong

1. Strong
2. Adequate

2. Adequate
3. Weak

3. Weak 


\section{Guideline 6: design as a search process}

6.1 Decomposition into sub-problems

6.2 Iteration from sub-problem solution to overall problem solution Yes

No

6.3 Satisficing used to decide on solution convergence point

Yes

No

\section{Guideline 7: communication of research}

7.1 Effectiveness of technology-oriented presentation

1. High 2. Medium

3. Low

7.2 Effectiveness of management-oriented presentation

8.1 Did the paper mention 'design science'? Yes

3. Low

8.2 If 'no', what did it call it?

$$
\text { Or 'nothing' }
$$

\section{Design science reference citations}

\begin{tabular}{ll}
\hline 1 & March and Smith (1995), DSS \\
2 & Markus et al. (2002), MISQ \\
3 & Nunamaker et al. (1991), JMIS \\
4 & Simon (1996 or earlier), The Sciences of the Artificial \\
5 & Walls et al. (1992), ISR \\
6 & Hevner et al. (2004), MISO \\
7 & Other \\
8 & None
\end{tabular}

10. Free text comments on the paper 